\title{
Investigation of the biosorption mechanisms of Methylene blue onto press mud through kinetic modeling analysis
}

\author{
R. Praveen Kumar ${ }^{1}$, Swambabu Varanasi ${ }^{2}$ and V.Purushothaman ${ }^{3}$ \\ School of Chemical and Biotechnology, Sastra University, Thanjavur, India \\ revurip@live.com
}

\begin{abstract}
This research deals with the highly available sugar industry waste material, press mud as low cost biosorbent for the removal of textile dyestuff from aqueous medium, and the investigation of the probably involved physiochemical mechanisms. Experiments were carried out in batch reactor. The results of equilibrium studies showed that equilibrium state was reached within $48 \mathrm{~h}$ of exposure time and maximum biosorption taken place at the biosorbent dosage of 30 $\mathrm{mg} / \mathrm{ml}$ of solution. Secondly, several biosorption kinetic models were applied to fit the experimental data, namely Lagergren irreversible first-order, Reversible first-order, Pseudo-second-order, Elovich and intraparticle diffusion models. The proposed explanations were deduced from the theoretical assumptions behind the most appropriate model(s), which could satisfactorily describe the present biosorption phenomenon. The interpretation of the related results have shown that, with $\mathrm{R}^{2}$ of about $99 \%$, the pseudo-second order model is the most suitable dynamic theory describing the biosorption of dye onto press mud predicting therefore a chemisorption process.
\end{abstract}

Keywords: Biosorption, press mud, dye, kinetic modeling.

\section{Nomenclature}

$a \quad$ Elovich initial sorption rate constant $\left(\mathrm{mg} \mathrm{g}^{-1} \mathrm{~h}^{-1}\right) ; a_{\bar{R}}$ Ritchie second-order rate constant $\left(\mathrm{mg} \mathrm{g}^{-1} \mathrm{~h}^{-1}\right) ; \mathrm{CO} \quad$ Initial concentration of dye in solution (mg/L); $\mathrm{Ce}$ equilibrium concentration of dye in solution $(\mathrm{mg} / \mathrm{L}) ; \mathrm{k}$ equilibrium rate constant for the reversible kinetic model $\left(=k_{1} / k_{-}\right)$; $k i$ intra particle diffusion rate constant (mg g_1 $\left.h \_1 / 2\right)$; $k 1$ forward reaction rate constant; $k \_1$ reverse reaction rate constant; $\mathrm{kl}$ rate constant of first-order kinetic model $\left(\mathrm{h}^{-1}\right)$ kll rate constant of pseudo-second-order kinetic model $(\mathrm{g} / \mathrm{mg} \mathrm{h})$; qe calculated amount of dye molecules adsorbed per unit of biomass $(\mathrm{mg} / \mathrm{g}) ; \mathrm{Q} \quad$ amount of dye molecules adsorbed per unit of biomass at time $\mathrm{t}(\mathrm{mg} / \mathrm{g}) ; \mathrm{Qa}$ experimental amount of adsorbed dye per unit of biomass at equilibrium ( $\mathrm{mg} / \mathrm{g})$; Q1 amount of adsorbed dye per unit of biomass at infinite time $(\mathrm{mg} / \mathrm{g}) ; \mathrm{R}_{2}$ squared regression correlation coefficient; $\mathrm{V}$ solution volume $(\mathrm{L})$; W weight of the dried press mud $(\mathrm{g}) ; \mathrm{X}$ equivalent dye concentration in the solid phase.

\section{Introduction}

Many industries, mostly textile industry, propagate colored effluents containing dyes and pigments. The discharge of dye wastewater in the environment is aesthetically undesirable and has serious environmental impact. The colored wastewater in the receiving streams reduces the light penetration through the water's surface and, therefore, reduces photosynthetic activity (Weisburger, 2002). Therefore, removal of such colored agents from aqueous effluents is of significant environmental, technical, and commercial importance.

Adsorption is the process by which a solid adsorbent can attract a component in water to its surface and form an attachment via a physical or chemical bond, thus removing the component from the fluid phase. The advantages of adsorption process are simplicity in operation, inexpensive compared to other separation methods and no sludge formation. Researchers have exploited many low cost, biodegradable and effective adsorbents obtainable from natural resources for the removal of different dyes from aqueous solutions at different operating conditions. Some of the materials used with varying success include: rice husk (Malik, 2003), rice hull (Ong et al., 2007), cotton seed shell (Kim et al.,2003), cornelian cherry and almond shell (Demirbas et al., 2004), hazelnut shell (Demirbas, 2003; Demirbas et al., 2002), coir pith (Kavitha \& Namasivayam, 2007), kernel shell (Jumasiah et al., 2005), corncob and barley husk (Robinson et al., 2002a), apple pomace and wheat straw (Robinson et al., 2002b), cellulose-based wastes (Annadurai et al., 2002), orange peel (Arami et al., 2005), palm fiber activated carbon (Tan et al., 2007) and beech sawdust (Batzias \& Sidiras, 2007) have been successfully employed for the removal of dyes from aqueous solutions.

In the present work, press mud a byproduct from sugar industry was used as low cost adsorbent for removing methylene blue from aqueous solutions. Being cheap precursor, it has been used as adsorbent. Several process parameters such as initial dye concentration, adsorbent dosage were explored. The rate limiting step of 
the basic dye onto the adsorbent was determined from the adsorption kinetic results.

Materials and methods

\section{Biosorbent}

Pressmud obtained from sugar industry dried and wash with double distilled water for removing proteins present in the waste for increasing active sites present in the adsorbent. Then it was oven dried at $60^{\circ} \mathrm{C}$ till it reached constant weight. The dried sample was crushed, sieved to a particle size range of $0.5-1 \mathrm{~mm}$, and stored in plastic bag for further use. No other chemical or physical treatments were used prior to adsorption experiments.

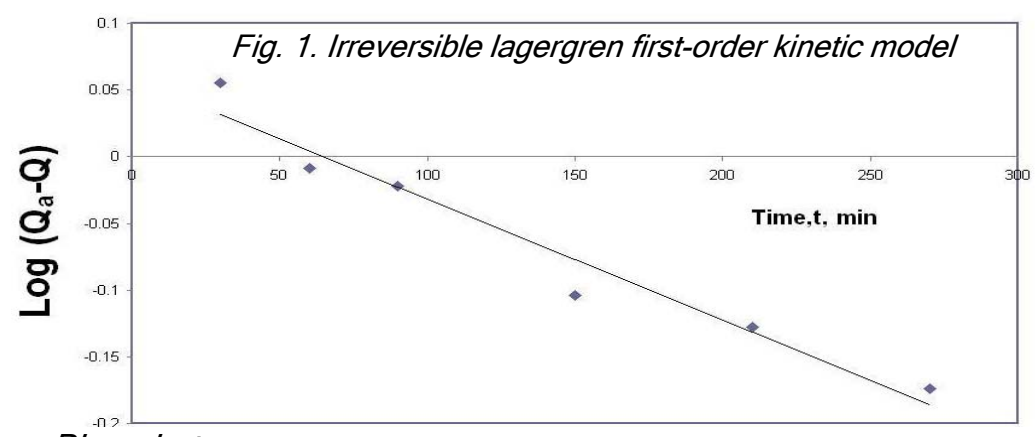

Scheme 1: Chemical structure of methylene blue<smiles>CN(C)c1ccc2nc3ccc(=[N+](C)C)cc-3sc2c1</smiles>

Cl modeling section. $d q / d t=k_{1}\left(Q_{a}-Q\right)$
Results and discussion Kinetic modeling in batch system

In order to mechanisms of the present biosorption

process and the potential rate controlling steps such as mass transport, pore diffusion and chemical reaction processes, kinetic models have been used to fit experimental data. The Lagergren irreversible first-order, Reversible first-order, Pseudo-second-order, Elovich and intra particle diffusion equations were used in this case assuming that measured concentrations are equal to cell surface concentrations. The rate parameters of all studied models will be presented and discussed separately at the end of this kinetic

Lagergren irreversible first-order model: The firstorder rate expression of Lagergren (1898), based on solid capacity, is generally expressed as follows:

After integration and applying boundary conditions, $t$

Biosorbate

The basic used in this study is methylene blue obtained from textile mill. The MB was chosen in this study because of its known strong adsorption onto solids. The maximum absorption wavelength of this dye is 630 $\mathrm{nm}$. The structure of MB is shown in Scheme 1.

\section{Biosorption studies}

Adsorption experiments were carried out by adding different amounts of adsorbent $(0.20 \mathrm{~g}, 0.50 \mathrm{~g}, 1 \mathrm{~g}, 2 \mathrm{~g}$, $2.5 \mathrm{~g}$ and $3.5 \mathrm{gm}$ ) into $250-\mathrm{mL}$ Erlenmeyer flasks containing $100 \mathrm{ml}$ aqueous dye solution with initial concentration $75 \mathrm{mg} / \mathrm{L}$ and $\mathrm{pH}$ 7.The flasks were agitated in an isothermal shaker at $120 \mathrm{rpm}$ and $30 \circ \mathrm{C}$. Aqueous samples were taken from the solutions and the concentrations were analyzed for every one hour. At time $t=0$ and at equilibrium (after 48 hours), the dye concentrations were measured by a double beam UV/vis spectrophotometer at $630 \mathrm{~nm}$.

Fiq. 2. Plot of reversible first-order kinetic model

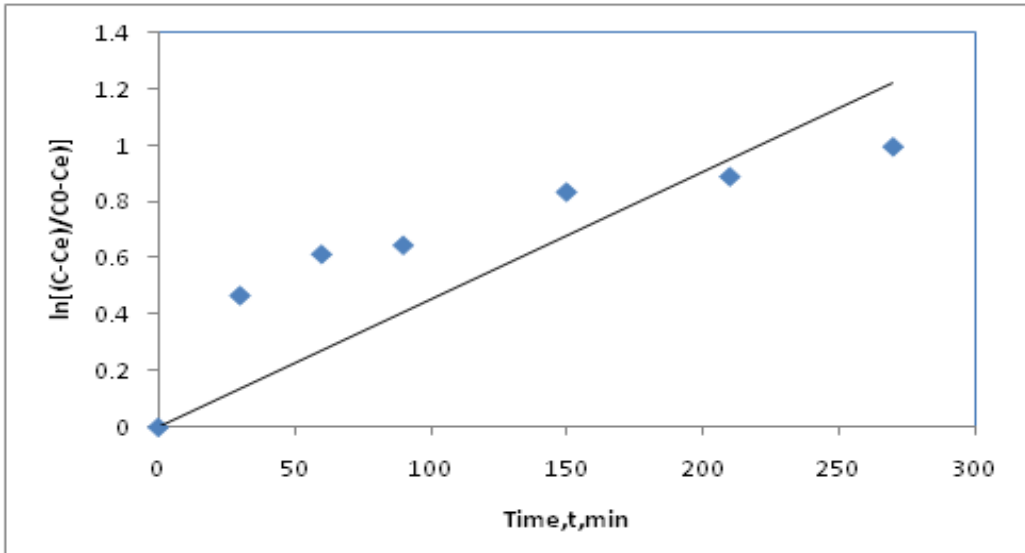

(1) becomes:

$\log \left(Q_{a}-Q\right)=\log q_{a}-k_{1}, t / 2.303$

The first-order rate constant $\mathrm{k}_{1}$ and the calculated $\mathrm{q}_{\mathrm{e}}$ values were determined, respectively, from the plots slopes and intercepts of $\log \left(Q_{a^{-}} Q\right)$ versus $t$ (Fig. 1). Commonly, inmost studied adsorption systems, the irreversible first-order equation does not fit well over the entire adsorption period and is generally applicable over the first 20-30 min of the sorption process. Such timelimited application of the Lagergren model was previously mentioned in the related scientific literature (Mohan et al., 2002; Aksu \& Donmez, 2003).

The reversible first-order model is derived on the assumption that the rate of the forward reaction $k_{1}$ (bioorption) and reverse rate $\mathrm{k}_{-1}$ (desorption) constants are equal to the equilibrium reaction rate constant $k$. Generally, it is assumed that the net rate of reaction could be expressed in terms of the forward rate constants $\mathrm{k} 1$ and the equilibrium rate constant $\mathrm{k}$.

$$
d c / d t=k_{1} c-k_{-1} c
$$

Besides, Eq. (4) gives the integrated form, from which the constants were determined:

$$
-\ln \left[\left(C-C_{g}\right) /\left(C_{0}-C_{g}\right)\right]=k_{i} t
$$

The plots of reversible first-order model are presented in Fig. 2.

Pseudo-second-order model. The pseudosecond-order equation (Ho \& McKay, 1999) is also based on the sorption capacity of the solid phase. If the rate of sorption is a second-order mechanism, the pseudo-second-order chemisorption kinetic rate equation is expressed
Research article

CIndian Society for Education and Environment (iSee)
"Biosorption of dye waste" http://www.indjst.org
Praveen Kumar et al. Indian J.Sci.Technol. 
Fig.3. Plot for Pseudo second order model

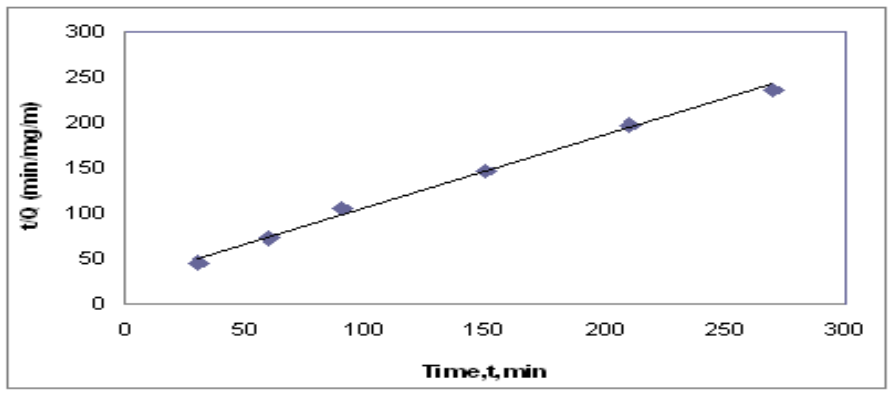

as

$d q / d t=k_{\pi}\left(Q_{a}-Q\right)^{2}$

For the boundary conditions $\mathrm{t}=0$ to $\mathrm{t}=\mathrm{t}$ and $\mathrm{Q}=0$ to $\mathrm{Q}=$ $\mathrm{Q}$; the integrated form of Eq. (5) becomes:

$t_{\mathrm{Q}}=1 / k_{n} \cdot q_{\mathrm{a}}^{2}+t^{t} / q_{\mathrm{g}}$

When this model is applicable, the plot of $t / Q$ against $t$ (Fig. 3) should give a linear relationship, from which $K_{\|}$ and calculated $\mathrm{q}_{\mathrm{e}}$ could be determined from the intercept and slope of the plot, respectively. Contrary to the Lagergren first-order, the pseudo-second-order model predicts the sorption behavior over the whole time biosorption (Ho, 2006).

Elovich modet. The Elovich equation, it is another rate equation based on the biosorption capacity, which is written as follows:

$d Q / d t=a \cdot e^{-\alpha Q}------(7)$

The integrated form of Eq. (7) can be expressed as:

$Q=\left(\frac{23}{a}\right) \cdot \log \left(t+\frac{1}{\alpha a}\right)-\left(\frac{23}{a}\right), \log \left(\frac{1}{\alpha a}\right)$

But, due to the complexity of the original Elovich equation, Chien and Clayton (1980) tried to simplify it by assuming that aat $>>1$ and by applying the boundary conditions of $Q=0$ at $\mathrm{t}=0$ and $\mathrm{Q}=\mathrm{Q}$ at $\mathrm{t}=\mathrm{t}$, then the integrated form of Eq. (7) becomes

$Q=\alpha \ln (\alpha x)+\alpha \ln (t)$

Thus, the Elovich kinetic constants could be deduced from the slopes and the intercepts of the linear plots of $Q$ against $\ln (\mathrm{t})$ (Fig. 4).

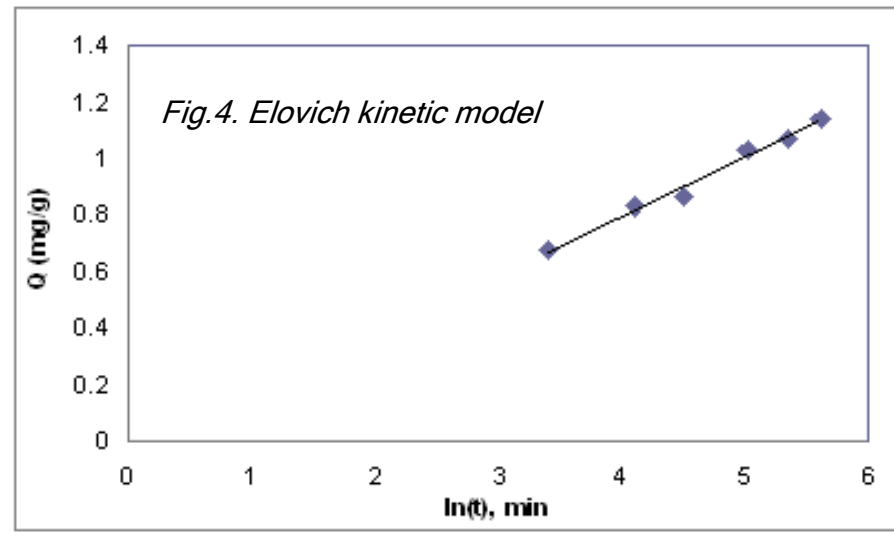

Vol. 3 No. 1 (Jan 2010)

ISSN: 0974- 6846

Intraparticle diffusion model: Sorption kinetic data was further processed to determine whether intra particle diffusion is rate limiting and also to find rate parameter for intra particle diffusion (ki). Weber and Morris (1963) intra particle diffusion model is characterized by the relationship between specific sorption and the square root of time, according to the following equation:

$$
k_{i}=Q / t^{0.5}
$$

The $k_{i}$ value can be obtained from the slope of the plot of $Q \quad(\mathrm{mg} / \mathrm{g})$ versus $\mathrm{t}^{0.5}$ (Fig. 5). Previously, several researchers showed that if this plot represents multilinearity in its shape, such behaviour characterizes two or more steps involved in the overall sorption process (Vadivelan \& Kumar, 2005). Indeed, the plots are of general type, i.e. initial curved and final linear portion. The initial curved portions may be attributed to the boundary layer diffusion effect, while the final linear portions may be due to intra particle diffusion effects (Crank, 1965). Therefore, the slope of this linear portion is defined as a rate parameter $\left(\mathrm{k}_{\mathrm{i}}\right)$ and characteristic of the biosorption rate.

Kinetic results interpretation: From a mechanistic point of view to interpret the kinetic experimental data, prediction of the rate-limiting step is an important factor to be considered in the sorption process (Vadivelan and Kumar, 2005). Although kinetic studies help to identify the sorption process, predicting the mechanisms is required for design purposes. For a solid-liquid sorption process, the solute transfer is usually characterized by either external mass transfer (boundary layer diffusion) for non

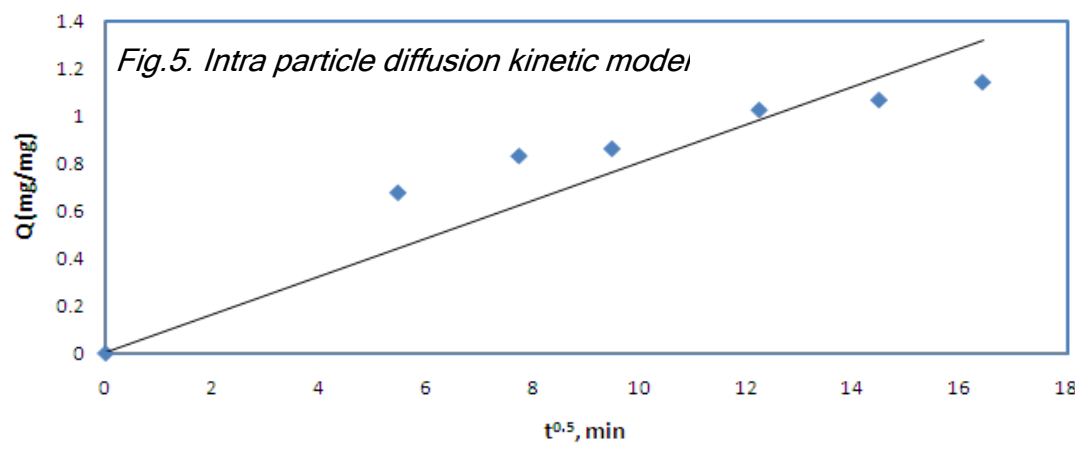

porous media or intra particle diffusion for porous matrices, or both combined.

According to the kinetic modeling results shown in Table 1, the correlation coefficients for both Lagergren irreversible and reversible first-order models obtained at all studied initial dye concentrations were low. Therefore, the reaction involved in the present biosorption system is not of the first-order.

On the other hand, the pseudo-second-order model shows the best fit to the experimental data related to the biosorption of methylene blue onto pressmud with the highest squared correlation coefficient. Thus, these results suggest that the pseudo-second-order model, based on the assumption that the rate limiting step might be chemical biosorption involving valency forces through
Research article

CIndian Society for Education and Environment (iSee)
"Biosorption of dye waste" http://www.indjst.org
Praveen Kumar et al. Indian J.Sci.Technol. 
sharing or exchange of electrons between dye anions and biosorbent, provides the best correlation of the dynamic data. Besides, the Elovich model was also found to be

Table 1. The biosorption kinetic model rate constants

\begin{tabular}{|c|c|c|c|c|c|c|c|c|}
\hline \multirow{2}{*}{$\begin{array}{l}\text { Parameter } \\
G_{0}(\operatorname{mg} / 1)\end{array}$} & \multicolumn{3}{|c|}{ irreversible first order } & \multicolumn{2}{|c|}{ reversible first order } & \multicolumn{3}{|c|}{ Pseudo-second order model } \\
\hline & $k_{1}$ & $\mathrm{qe}_{\mathrm{e}}$ & $\mathrm{r}^{2}$ & $k$ & $\mathrm{r}^{2}$ & $k_{\mathrm{ii}}$ & $\mathrm{qe}$ & $r^{2}$ \\
\hline 75 & 0.0021 & 1.06 & 0.95 & 0.04 & 0.6 & 0.024 & 1.25 & 0.995 \\
\hline
\end{tabular}

\begin{tabular}{cccccc} 
Parameter & \multicolumn{2}{c}{ Elovich Model } & & \multicolumn{2}{l}{ Intra particle diffusion model } \\
\cline { 5 - 6 } \cline { 5 - 6 } $\mathrm{C}_{0}(\mathrm{mg} / 1)$ & $\mathrm{k}_{1}$ & $\mathrm{r}^{2}$ & & $\mathrm{k}$ & $\mathrm{r}^{2}$ \\
\hline 75 & 0.005 & 0.98 & & 0.08 & 0.83
\end{tabular}

adequate to satisfactorily explain the present biosorption phenomenon with correlation coefficient value 0.984 , which consolidate the chemisorption hypothesis $(\mathrm{Ho}$, 2006).

On the other side, the intraparticle diffusion analysis of the sorption of methylene blue onto pressmud, shows that the depicted two phases plot suggest that the sorption process proceeds by surface sorption and intra particle diffusion. Thus, it could be concluded that the studied dye uptake process would to be controlled by chemisorption interactions-type at earlier stages and by intra particle diffusion at later stages.

Conclusion

Biosorption of methylene dye was demonstrated using pressmud. The needed time to reach the equilibrium state was 48 hours maximum biosorption dosage of $30 \mathrm{mg} / \mathrm{ml}$ of solution. Besides, kinetic modeling was carried out using five well known models. The deduced parameters and constants had shown that the pseudo-second order model is the most appropriate theory to satisfactorily describe the studied sorption process, followed by the Elovich model. Such tendency would predict that the ratelimiting step might be chemical adsorption (chemisorption) and not mass transport during the first stages of the sorption process and probably followed by an intra particle diffusion phenomenon in later stages.

\section{References}

1. Annadurai G, Juang RS and Lee DJ (2002) Use of cellulosebased wastes for adsorption of dyes from aqueous solutions. J. Hazard. Mater. B92, 263-274.

2. Arami M, Limaee NY, Mahmoodi NM and Tabrizi NS (2005) Removal of dyes from colored textile wastewater by orange peel adsorbent: equilibrium and kinetic studies. J. Colloid Interface Sci. 288, 371-376.

3. Asku Z (2001) Equilibrium and kinetic modeling of cadmium (II) biosorption by $C$. vulgaris in a batch system: effect of temperature. Sep. Purif. Technol. 21, 285-294.

4. Batzias FA and Sidiras DK (2007) Dye adsorption by prehydrolysed beech sawdust in batch and fixed-bed systems. Biores. Technol. 98, 1208-1217.

5. Chien SH and Clayton WR (1980) Application of Elovich equation to the kinetics of phosphate release and sorption in soils. Soil Sci. Soc. Am. J. 44, 265-268.

Research article

CIndian Society for Education and Environment (iSee) London. (4), 1-39. 29-33. 90-100.

"Biosorption of dye waste" http://www.indjst.org
Vol. 3 No. 1 (Jan 2010)

ISSN: 0974- 6846

6. Crank J (1965) Mathematics of diffusion. Clarendon Press,

7. Demirbas E (2003) Adsorption of Cobalt(II) from aqueous solution onto activated carbon prepared from Hazelnut Shells. Adsorp. Sci. Technol. 21, 951-963.

8. Demirbas E, Kobya M, Senturk E and Ozkan T (2004) Adsorption kinetics for the removal of chromium (VI) from aqueous solutions on the activated carbons prepared from agricultural wastes. Water SA. 30, 533-539.

9. Ho YS (2006) Review of second-order models for adsorption systems. J.Hazard Mater. B136, 681-689.

10. Ho YS and McKay G (1998) Sorption of dye from aqueous solution by peat. Chem. Eng. J. 70, 115-124.

11. Ho YS and McKay G (1999) Pseudo-second order model for sorption processes. Process Biochem. 34, 451-465

12. Jumasiah A, Chuah TG, Gimbon J, Choong TSY and Azni I (2005) Adsorption of basic dye onto palm kernel shell activated carbon: sorption equilibrium and kinetics studies. Desalination. 186, 57-64.

13. Kavitha D and Namasivayam C (2007) Experimental and kinetic studies on methylene blue adsorption by coir pith carbon. Biores. Technol. 98, 14-21.

14. Kim TY, Baek IH, Jeoung YD and Park SC (2003) Manufacturing activated carbon using various agricultural wastes. J. Ind. Eng. Chem. 9, 254-260.

15. Lagergren $S$ (1898) About the theory of so-called adsorption of soluble substances. K. Sven. Vetenskapsakad. Handl. 24

16. Malik PK (2003) Use of activated carbons prepared from sawdust and rice husk for adsorption of acid dyes: a case study of Acid Yellow 36. Dyes \& Pigments. 56, 239-249.

17. Mohan SV, Rao NC and Karthikeyan J (2002) Adsorptive removal of direct azo dye from aqueous phase onto coal based sorbents: a kinetic and mechanistic study. J. Hazard Mater. B90, 189-204.

18. Ong ST, Lee CK and Zainal Z (2007) Removal of basic and reactive dyes using ethylenediamine modified rice hull. Biores. Technol. 98, 2792- 2799.

19. Robinson T, Chandran B and Nigam P (2002a) Removal of dyes from an artificial textile dye effluent by two agricultural waste residues, corncob and barley husk. Environ. Inter. 28,

20. Robinson T, Chandran B and Nigam P (2002b) Removal of dyes from a synthetic textile dye effluent by biosorption on apple pomace and wheat straw. Water Res. 36, 2824-2830.

21. Tan IAW, Hameed BH and Ahmad AL (2007) Equilibrium and kinetic studies on basic dye adsorption by oil palm fibre activated carbon. Chem. Eng. J. 127, 111-119.

22. Vadivelan V and Kumar VK (2005) Equilibrium, kinetics, mechanism, and process design for the sorption of methylene blue onto rice husk. J. Colloid Interface Sci. 286,

23. Weber Jr, WJ and Morris JC (1963) Kinetics of adsorption on carbon from solution. J. Sanit. Eng. Div. Am. Soc. Civ. Eng. 89, 31-60.

24. Weber WJ and MorrisJC (1963) Kinetics of adsorption on carbon solution. J. Sanit. Eng. Div. ASCE. 89, 31-60.

25. Weisburger JH (2002) Comments on the history and importance of aromatic and heterocyclic amines in public health. Mutat. Res. 506- 507, 9-20.

Praveen Kumar et al. Indian J.Sci.Technol. 